\title{
Regional trends in birth weight in low- and middle-income countries 2013-2018
}

Irene Marete ${ }^{1^{*}} \mathbb{D}$, Osayame Ekhaguere ${ }^{2}$, Carla M. Bann³ , Sherri L. Bucher ${ }^{2}$, Paul Nyongesa ${ }^{1}$, Archana B. Patel ${ }^{4}$, Patricia L. Hibberd ${ }^{5}$, Sarah Saleem ${ }^{6}$, Robert L. Goldenberg' ${ }^{7}$, Shivaprasad S. Goudar ${ }^{8}$, Richard J. Derman ${ }^{9}$, Ana L. Garces ${ }^{10}$, Nancy F. Krebs ${ }^{11}$, Elwyn Chomba ${ }^{13}$, Waldemar A. Carlo ${ }^{12}$, Adrien Lokangaka ${ }^{14}$, Melissa Bauserman ${ }^{15}$, Marion Koso-Thomas ${ }^{16}$, Janet L. Moore ${ }^{3}$, Elizabeth M. McClure ${ }^{3}$ and Fabian Esamai ${ }^{1}$

\begin{abstract}
Background: Birth weight (BW) is a strong predictor of neonatal outcomes. The purpose of this study was to compare BWs between global regions (south Asia, sub-Saharan Africa, Central America) prospectively and to determine if trends exist in BW over time using the population-based maternal and newborn registry (MNHR) of the Global Network for Women'sand Children's Health Research (Global Network).

Methods: The MNHR is a prospective observational population-based registryof six research sites participating in the Global Network (2013-2018), within five low- and middle-income countries (Kenya, Zambia, India, Pakistan, and Guatemala) in threeglobal regions (sub-Saharan Af rica, south Asia, Central America). The birth weights were obtained for all infants born during the study period. This was done either by abstracting from the infants' health facility records or from direct measurement by the registry staff for infants born at home. After controlling for demographic characteristics, mixed-effect regression models were utilized to examine regional differences in birth weights over time.

Results: The overall BW meanswere higher for the African sites (Zambia and Kenya), $3186 \mathrm{~g}$ (SD $463 \mathrm{~g}$ ) in 2013 and $3149 \mathrm{~g}$ (SD $449 \mathrm{~g}$ ) in 2018, ascompared to Asian sites (Belagavi and Nagpur, India and Pakistan), $2717 \mathrm{~g}$ (SD450 g) in 2013 and $2713 \mathrm{~g}$ (SD $452 \mathrm{~g}$ ) in 2018. The Central American site (Guatemala) had a mean BW intermediate between the African and south Asian sites, $2928 \mathrm{~g}$ (SD 452) in 2013, and $2874 \mathrm{~g}$ (SD 448) in 2018. The low birth weight (LBW) incidence was highest in the south Asian sites (India and Pakistan) and lowest in the African sites (Kenya and Zambia). The size of regional differences varied somewhat over time with slight decreases in the gap in birth weights between the African and Asian sites and slight increases in the gap between the African and Central American sites.
\end{abstract}

Conclusions: Overall, BWmeans by global region did not change significantly over the 5-year study period. From 2013 to 2018, infants enrolled at the African sites demonstrated the highest BW means overall across the entire study period, particularly as compared to Asian sites. The incidence of LBW was highest in the Asian sites (India and Pakistan) compared to the African and Central American sites.

Trial registration The study is registered at clinicaltrials.gov. ClinicalTrial.gov Trial Registration: NCT01073475.

Keywords: Birth weight, Global network, Low birth weight, Neonatal mortality, Newborns

*Correspondence: mareteirene07@yahoo.com

${ }^{1}$ Moi University School of Medicine, Eldoret, Kenya

Full list of author information is available at the end of the article

\section{Background}

The weight of an infant at birth (BW) is a crucial anthropometric measurement associated with infant mortality [2-4]. Population BW statisticsare important measures of overall population health. However, in 
low- and low-middleincome countries (LMICs), BWs are not always measured, and when measured, they are often obtained and recorded inaccurately. Ideally, BW is measured within the first hours after delivery, before significant postnatal weight loss has occurred [1].

A newborn is defined as having normal BW if weight at birth is $\geq 2500 \mathrm{~g}$. Low birth weight (LBW), as defined by the World Health Organization (WHO),isa weight at birth that is less than $2500 \mathrm{~g}$ (up to and including $2499 \mathrm{~g}$ ). Infants with $\mathrm{BW}<2500 \mathrm{~g}$ are further categorized into low birth weight (LBW), 1500-2499 g; very low birth weight (VLBW), 1000-1499 g; and extremely low birth weight $(E L B W)<1000 \mathrm{~g}[1]$. There is an inverse relationship betweenBW and mortality; newborns with LBW have a higher risk of neonatal mortality and are also at risk for stunting, poor neurodevelopment, and adultonset diseases [2-4]. Worldwide, an estimated 15-20\% of all newbornsweigh $<2500 \mathrm{~g}$ at birth [5]. This translates to more than 20million births a year. TheWHO has a goal to reduce the LBW rate by $30 \%$ by the year 2025 [6]. In certain regions, there has been an increase in the incidence of LBW deliveries [7]. LMICs carry the highest burden of LBW infants. In 2015, three-quarters of the world'sLBWnewborns were born in three regions: south Asia (47\%), eastern and southern Africa (13\%) and west and central Africa (12\%) [5].

In the recent past, data from high-income countries such as the United States and the United Kingdom recorded an increasing trend in mean BW, with a concurrent decrease in the prevalence of LBW $[8,9]$. This finding prompts the question as to whether a similar trend is occurring in LMICs.Exploring temporal trends in BW are important to health care policymakers, especially if there are changes in or regression in medical care or nursing practices, or patterns related to health service access [10]. For example, lack of, or late access to comprehensive antenatal care, which is common in LMICs [11], is correlated with a higher risk of pregnancy and newborn complications, including LBW. Improving rates of prenatal care is associated with decreases in the risk of premature birth and LBW [12].

A major challenge in monitoring the incidence of LBW is that about $60 \%$ of newborn babies in LMICs are not weighed nor have BWre corded [5]. Population-based survey data often rely on retrospective maternal recall and modeled estimates, with statistical methods to adjust for underreporting and misreporting of BW. By contrast, the Global Network prospectively collectsBW data in a population-based maternal and newborn health registry (MNHR) insix sites within five LMIC's from sub-Saharan Africa (Kenya and Zambia), south Asia (Belgavi and Nagpur India; Pakistan), and Central America (Guatemala) [13]. The purpose of this study was to examine trends and regional variation of documented BW and LBW categories over time and to explore possible factors related to those trends in the Global Network MNHR.

\section{Methods}

We performed a longitudinal cohort analysis of all infants born to mothers enrolled in the MNHR of the Global Network between 2013 and 2018. For the analysis, all deliveries with a measured BW, obtained between day 0 and day 7 were included. We excluded multiple births, miscarriages, medically terminated pregnancies, and pregnancies of women living outside the predefined study cluster (Fig. 1). We also excluded from our analyses clusters within sites that started after 2013, or were closed prior to 2018.

For infants born in a health facility, the weight recorded by facility personnel was abstracted from the medical record. For infants born at home, study personnel visited the home and obtained the weight. These weights were measured by the study personnel, or in the case of Kenya by the village elder trained for the task using standard scales [14]. It is however important to note that, in most sites, accurate gestational estimation was not possible, and therefore not included in the analysis.Thus, it is not possible to say whether the birthweights were appropriate for gestational age or not.

\section{Data analysis}

We summarized maternal and neonatal demographic characteristics by year of enrollment. To examine possible demographic changes over time, we compared the characteristics of neonates born in 2013 to those in 2018, using $t$ tests for continuous variables and chi-square tests for categorical variables.

Means and standard deviations (SDs) for BW were computed by region and year. In addition, to account for possible demographic differences across the regions, we computed adjusted mean BWs by region and year, controlling for the following demographic characteristics: maternal age, education, parity, weight, height, infant sex, and time between birth and weight measurement. To compute the adjusted means, we fit a linear mixed-effect regression model of BWby region, year, and region by year interaction, controlling for demographic characteristics and including sampling cluster as a random effect. In addition, we tested for interactions between year and demographic characteristics to determine if birth weights changed for different demographic subgroups over time. In Kenya, maternal height was not routinely measured between 2013 and 2017, hence for this and other missing values on control variables (i.e., demographic characteristics), multiple imputation techniques was utilized. Analysis performed with 


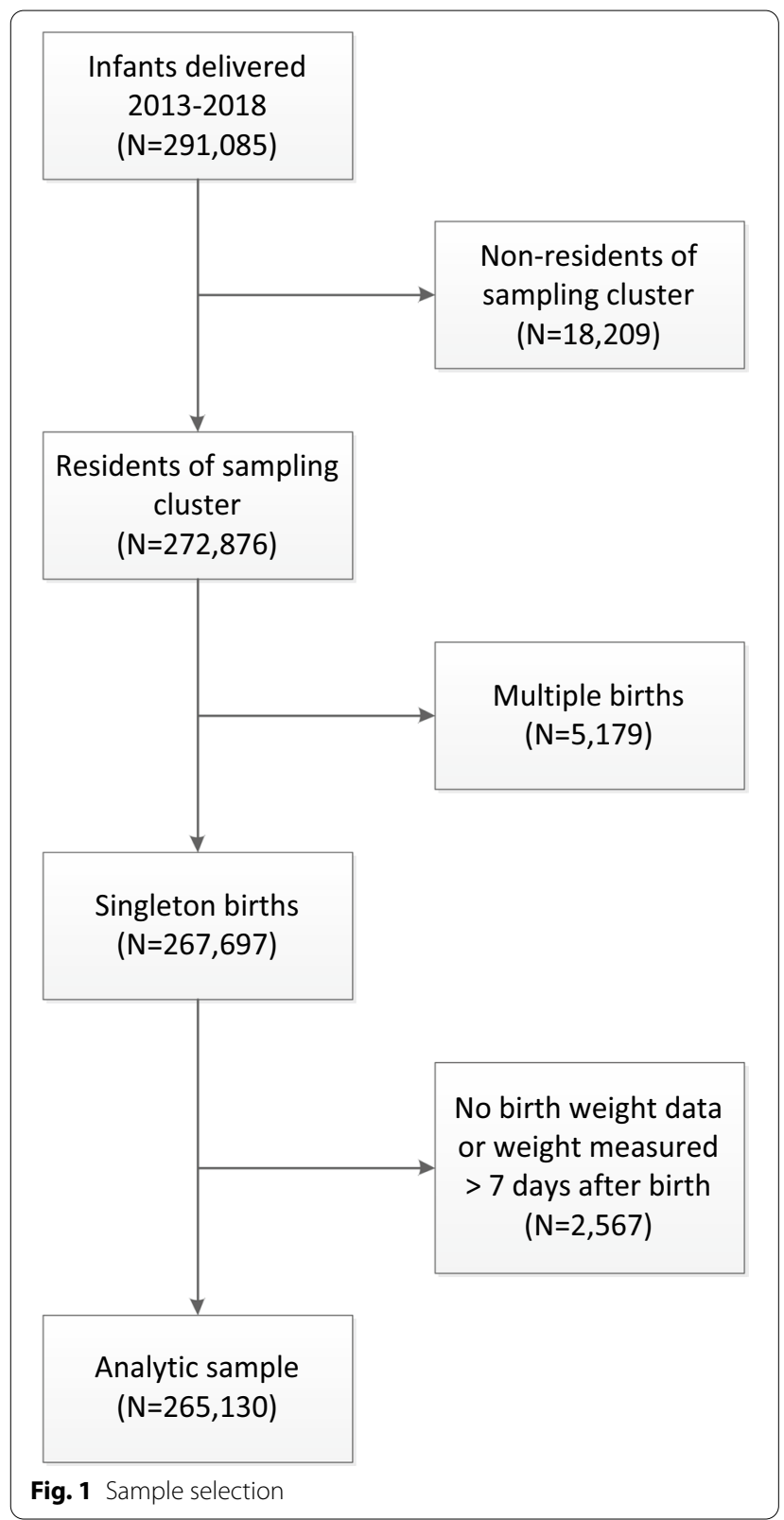

and without imputations were similar. Given the large sample sizes, we had a high level of statistical power, and therefore, even very small effects were found to be statistically significant. To determine whether significant changes in mean birth weights from 2013 to 2018 were meaningful, we examined Cohen's $d$ as a measure of effect size for which values of $0.2-0.4$ are considered small effects, $0.5-0.7$ are medium effects, and 0.8 or higher are large effects.Allanalyses were conducted using SAS version 9.4.

\section{Ethical consideration}

This study was reviewed and approved by all participating sites' ethics review committees/boards including review boards at each U.S. partner university and the data coordinating center (RTI International). All women provided informed consent for participation in the study, including data collection and the follow-up visits.

\section{Results}

Between 2013 and 2018, we enrolled 355,625 pregnant women in the MNHR. Of these, $1 \%(\mathrm{~N}=3254)$ were lost to follow up. Of the 291,085 deliveries captured in the MNHR within the study period, 265,130 (91\%) met inclusion criteria (Fig. 1). Of the singleton deliveries $(267,697)$, only $1 \%(2567)$ did not have a recorded birthweight in the MNHR.

\section{Maternal demographic by region}

As shown in Table 1, maternal age was generally similar across regions, with Central American women in our sample beingslightly older than African or Asian women.African women had slightly higher percentages of women with primary or secondary schooling. African women were heavier, especially compared to Asian women, and taller, especially as compared to Central American women.

\section{Birth weight difference by time period and region}

Eighty five percent of infants in the sample were weighed withintwo days after birth. Mean BW by region and year are shown in Table 2. Mean changes in BW (grams) from 2013 to 2018 by region were: Africa (36.51, $\mathrm{SD}=456.00)$; Asia (3.86, SD $=451.30$ ); and Central America (53.07, $\mathrm{SD}=450.20$ ). Change in birth weight over time was not statistically significant for Asia $(\mathrm{p}=0.389)$. While the changes in mean BW from 2013 to 2018 were statistically significant for Africa and Central America $(\mathrm{p}<0.001)$, these changes did not reach the threshold for even a small effect based on Cohen's d, suggesting that BW generally remained stable over time: Africa $(d=0.08)$, Asia $(\mathrm{d}=0.01)$, and Central America $(\mathrm{d}=0.12)$.

Birth weights of African newborns were consistently greater than that of Central American infants, which were likewise greater than BWs of Asian neonates. This pattern remained when BW was adjusted for region, year, and maternal demographics, although the size of the mean differences between regions changed slightly over time (Fig. 2).

\section{Birth weight categories by region}

Consistent with the pattern seen for mean BW,the African sites had the highest percentage of normal BW 
Table 1 Demographic characteristics by region

\begin{tabular}{|c|c|c|c|c|c|c|c|c|c|}
\hline \multirow[t]{2}{*}{ Characteristic } & \multirow{2}{*}{$\begin{array}{l}\text { Africa } \\
(\mathrm{N}=85,551)\end{array}$} & \multirow{2}{*}{$\begin{array}{l}\text { Asia } \\
(N=122,349)\end{array}$} & \multirow{2}{*}{$\begin{array}{l}\text { Central } \\
\text { America } \\
(\mathrm{N}=57,230)\end{array}$} & \multicolumn{2}{|l|}{ Africa vs. Asia } & \multicolumn{2}{|l|}{ Africa vs. CA } & \multicolumn{2}{|l|}{ Asia vs. CA } \\
\hline & & & & Mean $/ \%$ diff & $p$ value & Mean/\% diff & $p$ value & Mean $/ \%$ diff & $p$ value \\
\hline $\begin{array}{l}\text { Maternal age } \\
\text { (years), Mean } \\
\text { (SD) }\end{array}$ & $24.43(6.09)$ & $24.81(4.24)$ & $26.01(6.56)$ & -0.38 & $<0.001$ & -1.58 & $<0.001$ & -1.20 & $<0.001$ \\
\hline \multicolumn{10}{|c|}{ Maternal age (years), N (\%) } \\
\hline $11-19$ & $20,101(24)$ & $7165(6)$ & $9772(17)$ & 18 & $<0.001$ & 7 & $<0.001$ & -11 & $<0.001$ \\
\hline $20-35$ & $60,198(70)$ & $112,716(92)$ & $41,572(73)$ & -22 & $<0.001$ & -3 & $<0.001$ & 19 & $<0.001$ \\
\hline $36+$ & $5149(6)$ & $2454(2)$ & $5883(10)$ & 4 & $<0.001$ & -4 & $<0.001$ & -8 & $<0.001$ \\
\hline Nulliparous, N (\%) & $26,529(31)$ & $76,189(37)$ & $17,039(30)$ & -6 & $<0.001$ & 1 & $<0.001$ & 7 & $<0.001$ \\
\hline \multicolumn{10}{|l|}{ Education, N (\%) } \\
\hline $\begin{array}{l}\text { No formal edu- } \\
\text { cation }\end{array}$ & $3902(5)$ & $36,886(30)$ & $7583(13)$ & -25 & $<0.001$ & -8 & $<0.001$ & 17 & $<0.001$ \\
\hline $\begin{array}{l}\text { Primary/second- } \\
\text { ary }\end{array}$ & $77,313(90)$ & $73,006(60)$ & $46,323(81)$ & 30 & $<0.001$ & 9 & $<0.001$ & -21 & $<0.001$ \\
\hline University & $4230(5)$ & $12,394(10)$ & $3323(6)$ & -5 & $<0.001$ & -1 & $<0.001$ & 4 & $<0.001$ \\
\hline $\begin{array}{l}\text { Maternal } \\
\text { weight(kgs), } \\
\text { Mean (SD) }\end{array}$ & $60.19(9.51)$ & $46.68(8.05)$ & $56.70(9.48)$ & 13.51 & $<0.001$ & 3.49 & $<0.001$ & -10.02 & $<0.001$ \\
\hline $\begin{array}{l}\text { Maternal } \\
\text { height }(\mathrm{cm}) \\
\text { Mean (SD) }\end{array}$ & $158.74(6.72)$ & $152.93(5.65)$ & $147.10(5.45)$ & 5.81 & $<0.001$ & 11.64 & $<0.001$ & 5.83 & $<0.001$ \\
\hline Male infant, N (\%) & $43,179(50)$ & $63,443(52)$ & $29,175(51)$ & -2 & $<0.001$ & -1 & 0.052 & 1 & $<0.001$ \\
\hline $\begin{array}{l}\text { Facility birth, N } \\
(\%)\end{array}$ & $65,281(76)$ & 108,573 (89) & $33,135(58)$ & -13 & $<0.001$ & -18 & $<0.001$ & 31 & $<0.001$ \\
\hline $\begin{array}{l}\text { Number of days } \\
\text { between birth } \\
\text { and birth } \\
\text { weight meas- } \\
\text { urement, Mean } \\
\text { (SD) }\end{array}$ & $0.32(1.04)$ & $0.51(0.97)$ & $1.07(1.89)$ & -0.19 & $<0.001$ & -0.75 & $<0.001$ & -0.56 & $<0.001$ \\
\hline
\end{tabular}

CA Central America

(95.8\%), hence the lowest percentage of all low BW categories (3.9\% LBW, 0.3\% VLBW, and 0.1\% ELBW; Fig. 3). The Central American site was intermediate, with $84.4 \%$ normal BW and $15.6 \%$ across all LBW categories, and the Asian regional site had the lowest percentage of normal BW (79.8\%) and highest percentages of births in all LBW categories (20.2\%; Fig. 3).

\section{Discussion}

We examined trends, and regional differences in mean BW, between 2013 and 2018, of all newborns from six sites in five LMICs enrolled inthe Global Network MNHR. Overall, after controlling for maternal demographic characteristics, there appeared to be a consistent pattern of regional differences across the time period. The mean BW was generally found to be highest in the African regional site (Zambia and Kenya) as compared to the other regional sites, of South Asia (India and Pakistan) and Central America (Guatemala). Across the study period, there were slight changes observed in the size of these disparities over time, with the gap between the African and Asian sites decreasing, and the gap between the African and Central American sites increasing. These observations, however, may not be generalizable to the regions on whole, since the presence of the registry in these clusters may have exerted an influence (Hawthorne effect) on pregnancy outcomes over time.

The highest annual LBW rates were recorded in the Asian sites at $20.2 \%(18.6 \%, 1.1 \%$, and $0.5 \%$ for LBW, VLBW and ELBW respectively) and the Central American site at $15.6 \%(14.7 \%, 0.5 \%, 0.4 \%$ for LBW, VLBW and ELBW respectively). This is consistent with a 2019 UNICEF report, in which the LBW rate in south Asia was $28 \%$. However, the prevalence of LBW in Latin American was report to be $8.7 \%$, which was almost half of what our study reports [5]. Similar findings have also been reported in the WHO multicenter Growth Reference Study [15]. The LBW rate in the African sites in our study was $4 \%$. This result is similar to the proportion (3.5\%) reported in the Intergrowth21st study [16], but 
Table 2 Birth weights (g) by region and year

\begin{tabular}{|c|c|c|c|c|c|c|c|c|c|}
\hline \multirow{2}{*}{$\begin{array}{l}\text { Year } \\
\text { Unadjusted }\end{array}$} & \multirow{2}{*}{$\begin{array}{l}\text { Africa } \\
\text { Mean (SD) }\end{array}$} & \multirow{2}{*}{$\begin{array}{l}\text { Asia } \\
\text { Mean (SD) }\end{array}$} & \multirow{2}{*}{$\begin{array}{l}\text { Central America (CA) } \\
\text { Mean (SD) }\end{array}$} & \multicolumn{2}{|l|}{ Africa vs. Asia } & \multicolumn{2}{|l|}{ Africa vs. CA } & \multicolumn{2}{|l|}{ Asia vs. CA } \\
\hline & & & & Mean diff. (SD) & p value & Mean diff. (SD) & $p$ value & Mean diff. (SD) & $p$ value \\
\hline 2013 & $3186(463)$ & $2717(450)$ & $2928(452)$ & $469(455)$ & $<0.001$ & $258(459)$ & $<0.001$ & $-211(451)$ & $<0.001$ \\
\hline 2014 & $3172(454)$ & $2730(472)$ & $2922(451)$ & $441(465)$ & $<0.001$ & $249(453)$ & $<0.001$ & $-192(465)$ & $<0.001$ \\
\hline 2015 & $3168(458)$ & $2717(482)$ & 2909 (478) & $451(473)$ & $<0.001$ & $258(466)$ & $<0.001$ & $-193(481)$ & $<0.001$ \\
\hline 2016 & $3148(465)$ & $2716(477)$ & $2897(440)$ & $432(472)$ & $<0.001$ & $251(455)$ & $<0.001$ & $-181(465)$ & $<0.001$ \\
\hline 2017 & $3149(467)$ & $2714(464)$ & $2889(456)$ & $434(465)$ & $<0.001$ & $260(462)$ & $<0.001$ & $-174(461)$ & $<0.001$ \\
\hline 2018 & 3149 (449) & $2713(452)$ & $2874(448)$ & $436(451)$ & $<0.001$ & 275 (448) & $<0.001$ & $-161(451)$ & $<0.001$ \\
\hline \multirow{2}{*}{$\begin{array}{l}\text { Year } \\
\text { Adjusted }\end{array}$} & \multirow{2}{*}{$\begin{array}{l}\text { Africa } \\
\text { Mean (SE) }\end{array}$} & \multirow{2}{*}{$\begin{array}{l}\text { Asia } \\
\text { Mean (SE) }\end{array}$} & \multirow{2}{*}{$\begin{array}{l}\text { Central America (CA) } \\
\text { Mean (SE) }\end{array}$} & \multicolumn{2}{|l|}{ Africa vs. Asia } & \multicolumn{2}{|l|}{ Africa vs. CA } & \multicolumn{2}{|l|}{ Asia vs. CA } \\
\hline & & & & Mean diff. (SE) & $p$ value & Mean diff. (SE) & $p$ value & Mean diff. (SE) & $p$ value \\
\hline 2013 & 3105 (13) & $2757(10)$ & $2918(18)$ & $348(17)$ & $<0.001$ & $187(22)$ & $<0.001$ & $-161(20)$ & $<0.001$ \\
\hline 2014 & $3100(13)$ & $2755(10)$ & $2909(17)$ & $345(17)$ & $<0.001$ & $191(22)$ & $<0.001$ & $-154(20)$ & $<0.001$ \\
\hline 2015 & 3095 (13) & $2753(10)$ & $2901(17)$ & $342(17)$ & $<0.001$ & $194(22)$ & $<0.001$ & $-148(20)$ & $<0.001$ \\
\hline 2016 & 3089 (13) & $2751(10)$ & $2892(17)$ & $339(17)$ & $<0.001$ & $197(22)$ & $<0.001$ & $-141(20)$ & $<0.001$ \\
\hline 2017 & $3084(13)$ & $2748(10)$ & $2883(17)$ & $335(17)$ & $<0.001$ & $201(22)$ & $<0.001$ & $-135(20)$ & $<0.001$ \\
\hline 2018 & $3078(13)$ & $2746(10)$ & $2874(18)$ & $332(17)$ & $<0.001$ & $204(22)$ & $<0.001$ & $-128(20)$ & $<0.001$ \\
\hline
\end{tabular}

Adjusted means obtained from models with the following variables: year, region, year $\times$ region interaction, maternal age, parity, year $\times$ parity interaction, education, maternal weight, maternal height, infant sex, and time between birth and weight measurement

differs from $13 \%$ reported in the 2019 UNICEF report [5]. A possible explanation for this difference is that the data used for the UNICEF report were obtained from multiple sources and subjected to modeling. Up to $28 \%$ of the births in the UNICEF study hadno weight recorded, with the highest rates of missing $\mathrm{BW}$ data werereported to have occurred in Africa, where the rate ofmissing birthweight data was estimatedto be over 50\% [5]. By contrast, in the Global Network's prospective, population-based MNHR from 2013 to 2018, 85\% of the newborns were weighed at or within 2 days of birth.

Usually, the causes of LBW deliveries are multifactorial. Genetic and environmental factors play a significant role. Parity, low socioeconomic status, marital status, maternal age, nutritional status, maternal body mass index (BMI), maternal health status, smoking, alcohol intake, and prevailing infections such as from malariahave all been associated with BW outcomes [16-19]. There exist regional differences in the prevalence of certain diseases, such asmalaria, which has been reported to increase the odds of LBW deliveries [20-22]. Maternal genes in addition to other factors determine the intrauterine environment andmay vary with region and race [16]. In a study examining birth outcomes offilipina mothers living in Canada, BW among their babies was lower compared to infants of native Canadian mothers in the same environment [23]. Maternal diseases (e.g., diabetes and hypertensive disease) can also affect weight of a newborn. Socioeconomic status and other associated factors have been reported to influence BW.These determinants of BW vary across ethnic populations. It is still unclear to what extent the lower BW of some ethnic minority populations can be explained by these determinants $[24,25]$.

Some studies report a direct relationship between maternal age and BW. This relationship was demonstrated in a large cohort study in the United Statesbetween 2005 and 2014 [17]. The majority of mothers in our cohort were aged 20-35 years, with African sites and Asia sites having a lower maternal age compared to the Central American site. However, our Asian sites had the lowest rate of teenage pregnancies compared to the other two regions.

One limitation of our study is that not all BWs were measured on the same day, immediately after birth. The time a newborn weight is obtained may affect the recorded BW. However, in our study, this limitation is attenuated.The vast majority of all babies included in the analysis were weighed within $48 \mathrm{~h}$ of birth, and, for the entire sample, birthweights were acquired within one week of delivery. However, regional differences in time of weighing were also observed; African sites weighed the newborns closer to time of birth as compared to the Asian and Central American regional sites.

An additional potential source of bias in the results is the population of women who were entered into the study, but were lost to follow-up before the birth of the infant and measurement of BW. Our rates for loss-tofollow-up were quite low (1\%); however, it is possible that preterm and LBW infants are over-represented among infants lost to follow-up, resulting in bias 


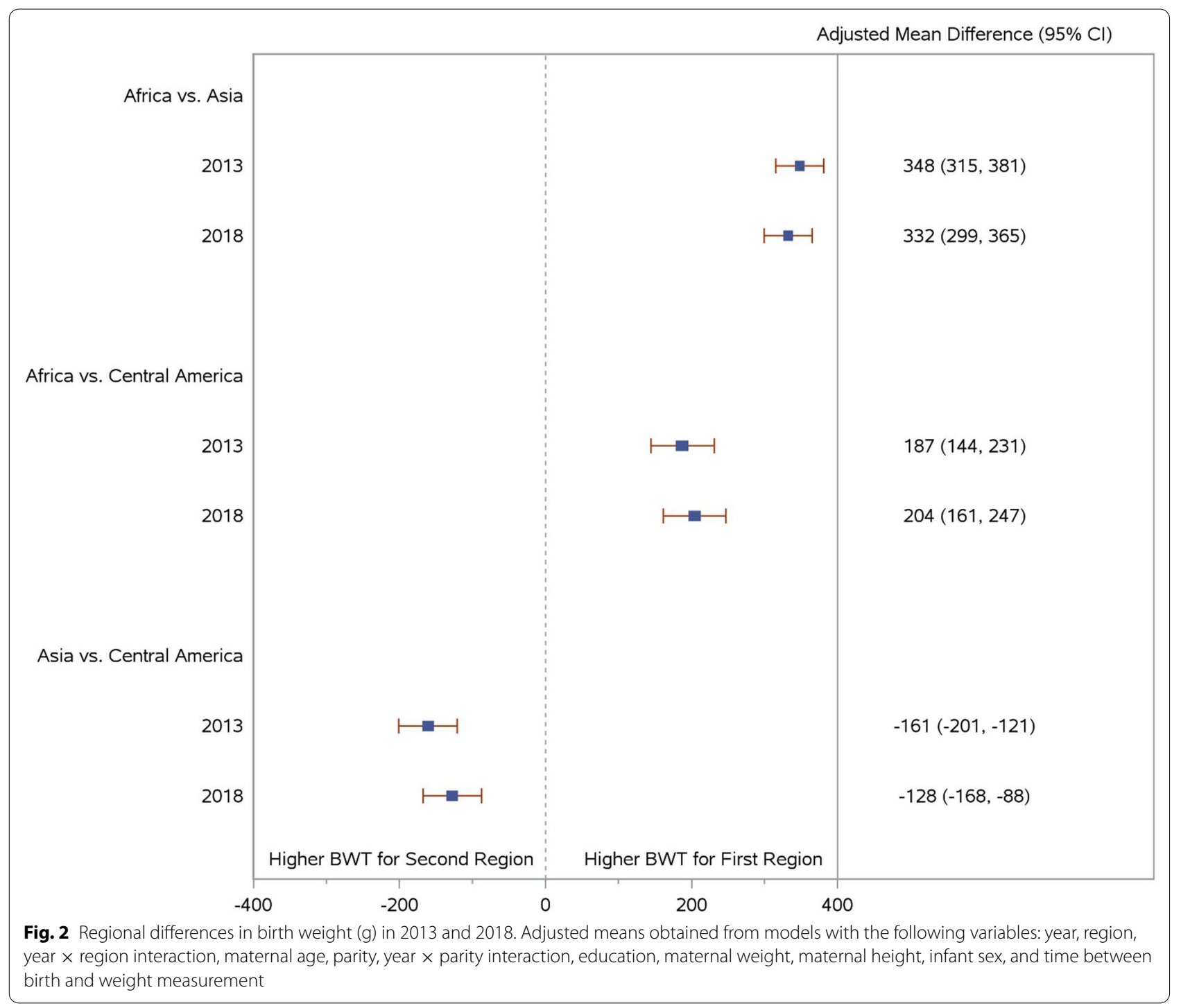

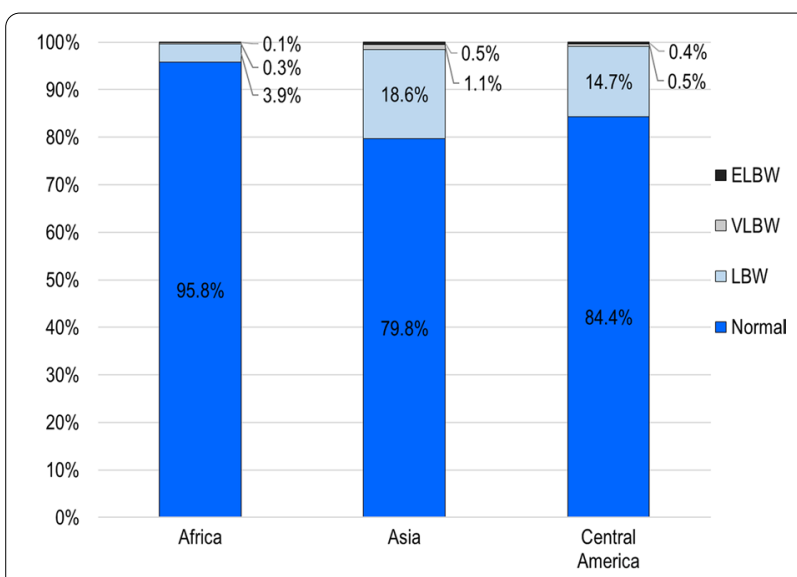

Fig. 3 Distribution of birth weight categories by region towards larger infants in the measured and reported population. Also, stillbirth and early neonatal deaths were likely to have their birthweights estimated instead of measured.

Observer errors have been reported in some studies of BW, as a result of digit preference. As an example, weights ending in 5 (five) or 0 (zero) tend to be preferred, as well as weights of multiples of 100 . This is especially problematic when a continuous BW variable is categorized. For instance, an infant with a measured BW of $2492 \mathrm{~g}$ may be recorded as 2500 , and hence categorized as a normal BW rather than LBW. Digit preference and rounding errors may result in over or underestimation, and therefore may affect observed BW trends [26]. Some infant weighing scales also tend to have readings to the nearest $50 \mathrm{~g}$ or nearest $100 \mathrm{~g}$, and this may underestimate the LBW rates. In our cohort, the process of obtaining 
and documenting birth weight is subject to this potential error.

A final limitation of our study is that the data were prospectively obtained from relatively small, discrete geographical areas (clusters) within each country. Hence, the data may not be representative of the country or region as a whole. However, as compared to other methods and data sources (e.g., Demographic Health Surveys) we enrolled an extremely large number of participants, prospectively, and followed standard procedures in obtaining and documenting weight, across sites, throughout the study period.

\section{Conclusions}

In a prospective, population-based, longitudinal cohort study of birthweight among three global regions, the observed BW meanshad no significant changeover time in aggregate or by region. In addition, theBWmeans recorded for African sites, as compared to the Asian sites, remained consistently higher.

The LBWrate was consistently higher in the Asian sites as compared to the African sites. The incidence of LBW observed for the two African sites in the MNHR was lower than that reported for other global estimates.

As compared to past regional estimates of BW, those obtained in the current study were determined from a very large sample of actual birthweights measured within sevendays of delivery. BW is impacted by a variety of complex maternal and environmental characteristics; future investigations should focus on determining the mechanistic underpinnings of regional and site differences in BW observed in this study.

\section{Abbreviations \\ BW: Birth weight; ELBW: Extremely low birth weight; GN: Global Network for Women's and Children's Health Research; LBW: Low birth weight; LMIC: Low and middle-income country; MNHR: Maternal and newborn health registry; SD: Standard deviation; VLBW: Very low birth weight; WHO: World Health Organization.}

\section{Acknowledgements}

The Authors gratefully acknowledge the contributions of the communities, women, and children who agreed to participate in this study, as well as the hard-working efforts of the field staff at each Global Network site.

\section{About this supplement}

This article has been published as part of Reproductive Health, Volume 17 Supplement 3, 2020: Global Network MNH. The full contents of the supplement are available at https://reproductive-health-journal.biomedcentral.com/ articles/supplements/volume-17-supplement-3.

\section{Authors' contributions}

IK participated in the data collection, drafted the manuscript and finalized the manuscript, OE revised, reviewed and and approved the manuscript, CM performed statistical analysis reviewed and approved the manuscript, SB study coordination, reviewed and approved the manuscript, PN participated in data collection study coordination,reviewed and approved the manuscript, AP participated in study design and coordination, reviewd and approved the manuscript, $\mathrm{PH}$ study dsign and coordination,reviewed and approved the manuscript, SS study design,coordination, reviewed and approved the manuscript, RG participated in study design,coordination,review and approval of the manuscript, SS participated in study design,coordination, review and approval of manuscript, RJ participated in study design, coordination, review and approval of manuscript, AL participated in study design, coordination, review and approval of the manuscript, NF participated in study design, coordination, review and approval of manuscript, EC coordination of the study, review of manuscript and approval, WA participated in study design, coordination, review and approval of manuscript, AL participated in study coordination review and approval of manuscript, MB participated in study design, coordination review and approval of manuscript, MK participated in study design coordination, review and approval of the manuscript, JL participated in data management, statistical analysis, review and approval of manuscript, EM participated in data management, review and approval of the manuscript, FE participated in study design, coordination review and approval of the manuscript. All authors read and approved the final manuscript.

\section{Funding}

Publication of this supplement is funded by grants from Eunice Kennedy Shriver National Institute of Child Health and Human Development NICHD to the participating sites and to RTI International.

\section{Availability of data and materials}

The dataset generated and analyzed during this study is not yet publicly available due to ongoing data analysis but it will be available in the NHCHDdata and specimen Hub. Request for data prior to public release will be handled by the author.

\section{Ethics approval and consent to participate}

At each site, institutional review boards or ethics committess approved the study. All women provided written informed consent before the start.

\section{Consent for publication}

The article was approved for publication by NICHD through its clearance mechanism.

\section{Competing interests}

The authors have no competing interest.

\section{Author details}

${ }^{1}$ Moi University School of Medicine, Eldoret, Kenya. ${ }^{2}$ Division of Neonatal-Perinatal Medicine, Indiana University School of Medicine, Indianapolis, IN, USA. ${ }^{3}$ RTI International, Durham, NC, USA. ${ }^{4}$ Lata Medical Research Foundation, Nagpur, India. ${ }^{5}$ Boston University School of Public Health, Boston, MA, USA. ${ }^{6}$ Aga Khan University, Karachi, Pakistan. ${ }^{7}$ Department of Obstetrics and Gynecology, Columbia University School of Medicine, New York, NY, USA. ${ }^{8}$ KLE Academy Higher Education and Research, J N Medical College Belagavi, Karnataka, India. ${ }^{9}$ Thomas Jefferson University, Philadelphia, USA. ${ }^{10}$ Instituto de Nutrición de Centroamérica y Panamá, Guatemala City, Guatemala. ${ }^{11}$ University of Colorado School of Medicine, Denver, CO, USA. ${ }^{12}$ University of Alabama at Birmingham, Birmingham, AL, USA. ${ }^{13}$ University Teaching Hospital, Lusaka, Zambia. ${ }^{14}$ Kinshasa School of Public Health, Kinshasa, Democratic Republic of Congo. ${ }^{15}$ University of North Carolina at Chapel Hill, Chapel Hill, NC, USA.

${ }^{16}$ Eunice Kennedy Shriver National Institute of Child Health and Human Development, Bethesda, MD, USA.

Received: 26 October 2020 Accepted: 28 October 2020 Published: 17 December 2020

\section{References}

1. International statistical classification of diseases and related health problems. 10th revision ed. , Geneva: World Health Organization; 2010 (ISBN 9789241548342 2).

2. Jornayvaz FR, Vollenweider P, Bochud M, Mooser V, Waeber G, MarquesVidal P. Low birth weight leads to obesity, diabetes and increased leptin levels in adults: the CoLaus study. Cardiovasc Diabetol. 2016;15:73. 
3. Gu H, Wang L, Liu L, Luo X, Wang J, Hou F, Nkomola PD, Li J, Liu G, Meng $H$, et al. A gradient relationship between low birth weight and IQ: a metaanalysis. Sci Rep. 2017;7(1):18035.

4. Christian P, Lee SE, Donahue Angel M, Adair LS, Arifeen SE, Ashorn P, Barros FC, Fall CH, Fawzi WW, Hao W, et al. Risk of childhood undernutrition related to small-for-gestational age and preterm birth in low- and middle-income countries. Int J Epidemiol. 2013;42(5):1340-55.

5. United Nations Children's Fund (UNICEF), World Health Organization(WHO). UNICEF-WHO Low birthweight estimates: Levels and trends 2000-2015. Geneva: WorldHealth Organization; 2019 (Licence: CC BY-NC-SA 3.0 IGO)

6. WHO. Global nutrition targets 2025: low birth weight policy brief (WHO/ NMH/NHD/14.5). Geneva: World HealthOrganization; 2014.

7. Islam MM. Increasing incidence of infants with low birth weight in Oman Sultan Qaboos Univ Med J. 2015;15(2):e177-183.

8. Johnson CD, Jones S, Paranjothy S. Reducing low birth weight: prioritizing action to address modifiable risk factors. J Public Health (Oxf). 2017:39(1):122-31.

9. Ghosh RE, Berild JD, Sterrantino AF, Toledano MB, Hansell AL. Birth weight trends in England and Wales (1986-2012): babies are getting heavier. Arch Dis Child Fetal Neonatal Ed. 2018;103(3):F264-70.

10. Weinberg CR. Invited commentary: troubling trends in birth weight. Am J Epidemiol. 2016;183(1):24-5.

11. Bucher S, Marete I, Tenge C, Liechty E, Esamai F, Patel A, et al. A prospective observational description of frequency and timing of antenatal care attendance and coverage of selected interventions from sites in Argentina, Guatemala, India, Kenya, Pakistan and Zambia. Reproductive Health. 2015;12(Suppl 2):S12.

12. Crockett $A H$, Heberlein EC, Smith JC, Ozluk P, Covington-Kolb S, Willis C. Effects of a multi-site expansion of group prenatal care on birth outcomes. Matern Child Health J. 2019;23(10):1424-33.

13. Bose C, Bauserman M, Goldenberg R, Goudar S, McClure E, Pasha O, et al. The Global Network Maternal Newborn Health Registry: a multi-national, community-based registry of pregnancy outcomes. Reprod Health. 2015;12(Suppl 2):S1

14. Gisore P, Shipala E, Otieno K, Rono B, Marete I, Tenge C, et al. Community based weighing of newborns and use of mobile phones by village elders in rural settings in Kenya: a decentralised approach to health care provision. BMC Pregnancy Childbirth. 2012;12(1):15.

15. Kiserud T, Piaggio G, Carroli G, Widmer M, Carvalho J, Neerup Jensen L, et al. The World Health Organization fetal growth charts: a multinational longitudinal study of ultrasound biometric measurements and estimated fetal weight. PLoS Med. 2017;14(1):e1002220.
16. Goldstein RF, Abell SK, Ranasinha S, Misso ML, Boyle JA, Harrison CL, et al. Gestational weight gain across continents and ethnicity: systematic review and meta-analysis of maternal and infant outcomes in more than one million women. BMC Med. 2018;16(1):153.

17. Ratnasiri AWG, Parry SS, Arief VN, DeLacy IH, Halliday LA, DiLibero RJ, Basford KE. Recent trends, risk factors, and disparities in low birth weight in California, 2005-2014: a retrospective study. Matern Health Neonatol Perinatol. 2018;4:15

18. Lunde A, Melve KK, Gjessing HK, Skjaerven R, Irgens LM. Genetic and environmental influences on birth weight, birth length, head circumference, and gestational age by use of population-based parent-offspring data. Am J Epidemiol. 2007;165(7):734-41.

19. Catov JM, Lee M, Roberts JM, Xu J, Simhan HN. Race disparities and decreasing birth weight: are all babies getting smaller? Am J Epidemiol. 2016;183(1):15-23.

20. Steketee RW, Nahlen BL, Parise ME, Menendez C. The burden of malaria in pregnancy in malaria-endemic areas. Am J Trop Med Hyg. 2001;64(1-2 Suppl):28-35.

21. McGregor IA, Wilson ME, Billewicz WZ. Malaria infection of the placenta in The Gambia, West Africa; its incidence and relationship to stillbirth, birthweight and placental weight. Trans R Soc Trop Med Hyg. 1983;77(2):232-44.

22. Brabin BJ. An analysis of malaria in pregnancy in Africa. Bull World Health Organ. 1983;61(6):1005-16.

23. De Souza LR, Urquia ML, Sgro M, Ray JG. One size does not fit all: differences in newborn weight among mothers of Philippine and other East Asian origin. J Obstetr Gynaecol Canada. 2012;34(11):1026-37.

24. Martinson ML, Reichman NE. Socioeconomic inequalities in low birth weight in the United States, the United Kingdom, Canada, and Australia. Am J Public Health. 2016;106(4):748-54.

25. Mahumud RA, Sultana M, Sarker AR. Distribution and determinants of low birth weight in developing countries. J Prev Med Public Health. 2017:50(1):18-28.

26. Emmerson AJ, Roberts SA. Rounding of birth weights in a neonatal intensive care unit over 20 years: an analysis of a large cohort study. BMJ Open. 2013:3(12):e003650.

\section{Publisher's Note}

Springer Nature remains neutral with regard to jurisdictional claims in published maps and institutional affiliations.
Ready to submit your research? Choose BMC and benefit from:

- fast, convenient online submission

- thorough peer review by experienced researchers in your field

- rapid publication on acceptance

- support for research data, including large and complex data types

- gold Open Access which fosters wider collaboration and increased citations

- maximum visibility for your research: over 100M website views per year

At BMC, research is always in progress.

Learn more biomedcentral.com/submissions 